\title{
Aprendizaje-Servicio Virtual y Pedagogía Social. El proyecto ProAcción Social
}

\section{Virtual Service-Learning and Social Pedagogy. The ProAcción Social project}

Alexandre Sotelino-Losada; alexandre.sotelino@usc.es

Universidade de Santiago de Compostela (España)

Millán Brea-Castro; millan@uvigo.es

Universidade de Vigo (España)

\section{Resumen}

El uso de la red social Instagram abre un amplio espacio a propuestas educativas que no sólo tienen que ver con la difusión de imágenes y vídeos, la relación casual a través de "likes" o las conversaciones privadas. Ofrece también la posibilidad de intercambio de conocimientos e información académica desde una perspectiva asíncrona, dinámica y no paternalista.

Este trabajo presenta los resultados de una experiencia de aprendizaje-servicio virtual donde el alumnado del Grado de Educación Social ha incluido esta plataforma en su dinámica de trabajo académico. El objetivo es visibilizar el perfil profesional de las/los educadoras/es sociales, al tiempo que investigan sobre diferentes necesidades circundantes para sensibilizar $y$ reclamar de manera pública una intervención ajustada.

Para el análisis de los datos hemos utilizado una metodología mixta con datos cualitativos (informes de trabajo y reflexiones grupales) y cuantitativos (impacto de publicaciones) tomados longitudinalmente. Finalmente podemos destacar que el uso de Instagram en las aulas universitarias promueve la consolidación de una identidad profesional en Educación Social y también contribuye a la participación e inclusión de todo el alumnado en el grupo aula. Por último, también se cubre una necesidad social, base en el ApS, contrarrestando prejuicios vinculados a colectivos vulnerables.

Palabras clave: Redes Sociales, Pedagogía Social, Aprendizaje-Servicio, Educación Superior, Digitalización.

\section{Abstract}

The use of Instagram opens a wide space for educational proposals that not only have to do with the dissemination of images and videos, the casual relationship through "likes", or private conversations. It also offers the possibility of exchanging knowledge and academic information from an asynchronous, dynamic and nonpaternalistic perspective.

This paper presents the results of a virtual servicelearning experience where the students of the Degree in Social Education have included this platform in their academic work dynamics. The objective is to make visible the professional profile of the social educators, while investigating different surrounding needs to raise awareness and publicly demand an adjusted intervention.

For data analysis we have used a mixed methodology with qualitative data (work reports and group reflections) and quantitative data (impact of publications) taken longitudinally. Finally, we can highlight that the use of Instagram in university classrooms promotes the consolidation of a professional identity in Social Education and also contributes to the participation and inclusion of all students in the classroom group. Finally, a social need, based on the SL, is also covered, counteracting prejudices linked to vulnerable groups.

Keywords: Social Networks, Social Pedagogy, Service-Learning, Higher Education, Digitization. 


\section{INTRODUCCIÓN}

En pleno siglo XXI, las tecnologías de la información y de la comunicación representan un sistema propio de intercambio, de gestión y de relación entre la juventud española. Su uso está extendido en los diferentes ámbitos que conforman su dimensión social, familiar y educativa. Son generaciones digitales y tecnológicas que nacieron ya inmersas en las TIC, es decir, no existe una adaptación ni un cambio de un sistema de comunicación y entretenimiento analógico a otro digital, como ocurre con las personas adultas (Cervera, 2009; Escandell, 2020; Peña et al., 2018; INJUVE, 2009).

Este hecho genera nuevos modelos de relación entre la gente joven: mayor capacidad de adaptación a los cambios e innovaciones tecnológicas, destreza en el uso y exploración de posibilidades de las TIC, búsqueda de nuevas experiencias y sensaciones, necesidad de estar actualizados e incluso, la capacidad para adelantarse a sus compañeras haciéndose con los últimos dispositivos y tecnologías disponibles en el mercado, descartando los viejos con independencia de su utilidad (Barba y Capella, 2010; Blaszczynsky, 2006; Cotino, 2010).

Pero teniendo en cuenta estas variables, surgen a diario conflictos respecto a su propio uso: horario y tiempo en el que están conectadas, espacios virtuales que frecuentan habitualmente, relaciones personales gestionadas solamente a través de las redes sociales, exposición de su vida pública o, problemas de comunicación debido a la interpretación que cada persona hace de los mensajes recibidos (Christahkis y Fowler, 2010; Echeburrúa, 2010; Gracia et al., 2002; Roig, 2010).

Resulta manifiesto que la principal motivación para conectarse a los diversos entornos virtuales es mantener la relación con iguales y seguir comunicadas en los horarios que no comparten espacio físico, y para ello su principal herramienta son las redes sociales. En este caso, no podemos hablar de aislamiento por parte de la juventud en el momento de usar los dispositivos, ya que son utilizados precisamente para comunicarse (Castillejos, 2019).

En este sentido, el fomento por tanto de una participación virtual ética, de la necesidad por generar conciencia crítica o simplemente, por entender la formación reglada como básica para el ejercicio de una profesión de carácter social, se convierte a día de hoy en el principal reto del profesorado universitario. Es decir, que enseñar al alumnado a pensar y a su vez ejercer la reflexión crítica es una meta que frecuentemente mencionamos como inherente a la función docente (Martínez-Salanova, 1999). Y hacerlo, en una sociedad de estímulos constantes, con un colectivo que pasa de estar en la educación secundaria a la universidad, con los cambios personales y familiares que genera, es una oportunidad que, desde la función docente, debemos asumir y aprovechar (Fernández-Rodríguez, 2004; Sotelino, 2019). En este sentido, existen varias experiencias que caminan en esta dirección, indicando su eficacia académica (Gómez-Arruzazabala, 2019; Bonilla et al., 2019; Escandell, 2020; Pérez-Escoda, 2018; Romero et al., 2019). Esa transferencia de contenido a través de medios digitales puede permitirnos mejorar procesos de enseñanza en el ámbito de la Educación Superior, dónde esa sensación de libertad y autonomía es mucho mayor que en ciclos anteriores (Castellana et al., 2006). Así, en la siguiente propuesta, aprovechamos una red social concreta, como es Instagram, para persuadir y facilitar la participación de los estudiantes de Educación Social, y generar que su mensaje llegue a un colectivo similar y mucho más amplio: sus iguales. 
En este sentido, el aprendizaje-servicio (ApS) no puede ser ajeno al nuevo contexto social, motivo por el que, en su condición de catalizador de vínculos entre universidad y comunidad, también ha de ofrecer posibilidades para conectar al alumnado con un mundo global que trasciende ya no sólo al aula, sino también al entorno más próximo. Esta metodología de carácter experiencial no es ajena a los cambios sociales, y se ha ido adaptando a nuevos escenarios como es la virtualidad. El ApS electrónico (o virtual) refiere a aquellos proyectos donde el componente instruccional, o la actividad de servicio, o bien ambas, tienen lugar virtualmente (Waldner, McGorry, y Widener, 2012). Ahora bien, no conviene postular una definición diferenciada a la modalidad tradicional, en tanto que la especificidad viene dada únicamente por la utilización de las tecnologías a fin de dar soporte a la implicación de los participantes o al desarrollo de las diferentes actividades del proyecto (García-Gutiérrez et al., 2017). Lo que sí resulta innegable es la extensión que este tipo de proyectos han tenido en los últimos tiempos, pues se puede llegar a afirmar, en gran medida, que se han conformado como la principal respuesta del ApS a la pandemia de la COVID-19 (García-Gutiérrez et al., 2021).

En definitiva, y siguiendo esta argumentación, procedemos a presentar un proyecto de aprendizaje-servicio virtual que pone su atención en una necesidad como es la de utilizar las nuevas redes de comunicación social como un canal para combatir fake news y prevenir los prejuicios en relación a diferentes problemáticas comunitarias. El objetivo es sensibilizar y prevenir conductas nocivas en jóvenes usuarios de redes sociales, y para ello se establece una dinámica participativa en la Universidad de Vigo que pone el foco en tal fin.

\section{EL PROYECTO “PROACCIONSOCIAL": TIC Y PEDAGOGÍA SOCIAL}

"Proaccionsocial" recibe el nombre de un perfil de Instagram creado como sugerencia de intervención educativa en enero de 2018, por el profesor y alumnado de 1 으 de Educación Social de la Facultad de Ciencias de la Educación del Campus de Ourense, Universidade de Vigo. Este perfil tuvo acceso libre para todas las alumnas que estuviesen interesadas en seguir sus publicaciones e imágenes, así como para participar en sus debates diarios.

Los centros de enseñanza, y en especial la Universidad constituyen un espacio privilegiado para conocer las inquietudes de la juventud y sus problemáticas, y es también un contexto de referencia para las jóvenes que pasan en sus instalaciones buena parte del día (Sotelino et al., 2016). Por tanto, es inevitable que las tecnologías estén presentes en las aulas pero, a diferencia de su tiempo de ocio, que lo realizan de manera voluntaria, en este caso tuvo una finalidad pedagógica, sirviendo como herramienta de apoyo al aprendizaje $y$, como expositor de los contenidos trabajados en la materia de "Educación: Pedagogía Social". Este es el punto de partida clave: la diferenciación entre el uso que se puede hacer de las nuevas tecnologías a diario y en tiempos de ocio, y el aprovechamiento máximo de sus posibilidades sin desatender los intereses del alumnado y profesorado (Ruiz-Olivares et al., 2010). Además, así conseguimos que currículum y servicio no se separen y se mantengan en un mismo proyecto, condición indispensable en cualquier proyecto de aprendizaje-servicio (Santos-Rego et al., 2020).

Por tanto, consideramos que el aula (y sus momentos de esparcimiento posteriores) eran idóneos para el abordaje de este tema, fomentando el conocimiento de la materia tanto para las participantes, como para los potenciales destinatarios/as en las redes sociales. Aun así, 
surge una pregunta clara ¿Y cómo un perfil de Instagram, con carácter académico, puede generar interés informativo en una población destinataria?

Durante estos últimos 10 años, el cambio de plataformas digitales que utilizan fue enorme: pasando de redes sociales más estáticas (como Tuenti), que simulaban a otras redes para gente más mayor (Facebook), a otras mucho más dinámicas y en las que se podía curiosear a través de imágenes (Instagram o Twitter). Esta evolución, obliga a valorar que plataforma sería la más adecuada y, nos lleva a pasar un breve cuestionario al alumnado para conocer sus intereses, y que redes sociales utilizan con más asiduidad y también, indagar cobre cuál es el objetivo más común para emplearlas (INTECO, 2009).

Una vez superada esta primera fase, la programación se establece durante 10 semanas del segundo cuatrimestre. En cada una de las clases teóricas, se propone un contenido relacionado con la materia, un caso práctico real a resolver y, una imagen que debe establecer relación con dicha explicación. Previamente, también se definen los equipos de trabajo. Con esta premisa, incluimos en nuestras dinámicas el trabajo cooperativo en aula atendiendo a las premisas de interrelación positiva, heterogeneidad, responsabilidad individual y un resultado tanto individual como grupal (Santos et al., 2009).

Tras fijar grupos, programación y sistematización se proponen dos objetivos principales. Por un lado, el que vincula al alumnado a la hora de trabajar con el perfil de Instagram, dando a conocer la profesión de Educadores/as Sociales desde un punto de vista dinámico y accesible, teniendo en cuenta que es necesario establecer pautas didácticas claves que faciliten la compresión a colectivos y personas que desconocen totalmente la profesión (GonzálezHernando et al., 2020; Peña et al., 2018). Y por otro lado, la premisa que persigue el docente, que sería facilitar contenidos claves sobre Pedagogía, Educación Social y términos afines, así como motivar que las alumnas formen parte del proceso de adquisición y explicación de estos conocimientos. Una vez más se incide en la premisa del proyecto de ApS de vincular contenidos académicos y cívico-sociales junto con el servicio a la comunidad por medio de las Redes Sociales.

Entramos ahora en una segunda fase del proyecto, y para ello, con el fin de diseñar la intervención, se valora que este espacio virtual, sea el principal medio de comunicación y expresión entre el alumnado. Pasando un cuestionario en línea previo, que establece que prácticamente un $90 \%$ de las personas matriculadas tienen Instagram, y el $85 \%$ lo utilizaba de manera habitual (como mínimo una vez por semana). Dato que se viene repitiendo a lo largo de las cuatro ediciones de este proyecto. Incluso, crece su importancia si la comparamos con otras redes y si, valoramos que este colectivo se desconocía antes de comenzar las clases y que este "mundo virtual" les permitía la relación con sus compañeras/os de aula (además de la mensajería instantánea).

Instagram, por tanto, es un sistema integrado en su marco social. Sin embargo, el hecho de ocupar un espacio tecnológico y virtual hace que ambos sistemas (virtual y físico) tuviesen distintas estructuras. A través de las tecnologías que manejan en el día a día, gestionaban, por este orden: acceso a contenidos (información, música), entretenimiento y ocio, información con otras usuarias, interacción y comunicación con otras personas, presencia en comunidades virtuales, participación en espacios de opinión, gestión de datos personales y administrativos y, la compra y venta de artículos. Para que la intervención resulte atractiva, es necesario 
conocer mejor este uso y provocar en ellas/os la necesidad de convertir una red en un reto, en un desafío social (García-Ruiz et al., 2018).

De este modo, y ya en una tercera fase, se formuló la implementación de las propuestas desde una línea de trabajo de aula interactiva. Se pretendía huir del modelo de trabajo clásico de entrega documental, para abogar por un diálogo y negociación entre todas las alumnas/os, para que fueran ellas/os quienes expresasen su visión, dudas, experiencias, e incluso hicieran sugerencias respecto a los contenidos. De este modo desarrollamos un vínculo identitario con el proyecto que en última instancia siempre repercutirá en un incremento de motivación intrínseca del alumnado, y en la consecución de logros desde la autorrealización.

En la implementación de esta tercera fase, se identifican los contenidos entre conceptos y casos prácticos (Tabla 1), dividiéndose a su vez en diez propuestas a través de las cuáles se intenta favorecer un clima de trabajo cooperativo, acreditando un espacio donde poder compartir experiencias, fomentando la creatividad, coordinando la participación, y en la que se auspicie una respuesta dinámica por parte de los grupos.

\section{Tabla 1}

\section{Contenidos y bloques del proyecto}

\begin{tabular}{|c|c|}
\hline Bloque & Contenido \\
\hline 1. Pedagogía Social & $\begin{array}{l}\text { En esta primera publicación, se pretendía explicar un concepto clave de la } \\
\text { materia y se proponía como caso práctico, reflexionar sobre las conexiones de la } \\
\text { materia con su futura profesión de educadoras/es sociales (Caride, 2005). }\end{array}$ \\
\hline 2. Educación Social & $\begin{array}{l}\text { Para esta segunda actualización, el objetivo era doble, por un lado, explicar que } \\
\text { significaba su profesión y, aplicarlo en un caso práctico abordando una reunión } \\
\text { virtual con la Concejala de Servicios Sociales del Ayuntamiento de Ourense para } \\
\text { persuadirla sobre la importancia de contar con estos profesionales específicos } \\
\text { en su ciudad (Petrus, 1997). }\end{array}$ \\
\hline $\begin{array}{l}\text { 3. Educación } \\
\text { Permanente }\end{array}$ & $\begin{array}{l}\text { En este caso, el supuesto trataba sobre actividades o propuestas que deberían } \\
\text { realizar en una entidad como Aulas de la Tercera Edad. }\end{array}$ \\
\hline $\begin{array}{l}\text { 4. Educación } \\
\text { especializada }\end{array}$ & $\begin{array}{l}\text { Para la cuarta actualización, las definiciones variaron y se centraron en colectivos } \\
\text { diversos, y la propuesta práctica giraba en torno a una dinámica de prevención } \\
\text { de consumo de alcohol entre jóvenes. }\end{array}$ \\
\hline 5. Sororidad & $\begin{array}{l}\text { Coincidiendo con el } 8 \mathrm{M} \text {, y sus manifestaciones en las calles de toda España se } \\
\text { motiva una reflexión global respecto a la igualdad de oportunidades y la } \\
\text { educación en género, el alumnado propuso este concepto y, como práctica, } \\
\text { establecer claves sobre el amor romántico y las relaciones de pareja. }\end{array}$ \\
\hline $\begin{array}{l}\text { 6. Educación Cívico- } \\
\text { Social }\end{array}$ & $\begin{array}{l}\text { Como cuestión práctica, se plantea la creación de una empresa: si sería viable en } \\
\text { nuestro sector, con que colectivos actuaría o bien, si tendría posibilidades de } \\
\text { asentarse socialmente. }\end{array}$ \\
\hline $\begin{array}{l}\text { 7. Diferencias entre } \\
\text { trabajo social y } \\
\text { educación social }\end{array}$ & $\begin{array}{l}\text { Uno de los tópicos más asentados en este Grado, es la lucha entre dos } \\
\text { profesiones como el trabajo y la educación social. Para ello, se plantea una } \\
\text { situación en torno a una comida familiar y, como podríamos defender nuestra } \\
\text { profesión distinguiéndola de otras similares. }\end{array}$ \\
\hline $\begin{array}{l}\text { 8. Funciones del } \\
\text { educador/a social en la } \\
\text { Administración Local }\end{array}$ & $\begin{array}{l}\text { Una vez analizadas las funciones que, podría desarrollar un/a educador/a social } \\
\text { dentro de un Ayuntamiento, se consulta sobre un caso concreto vinculado al }\end{array}$ \\
\hline
\end{tabular}




\begin{tabular}{|c|c|}
\hline Bloque & Contenido \\
\hline & $\begin{array}{l}\text { denominado "botellón" y que soluciones aportarían en el caso de trabajar en la } \\
\text { Administración local. }\end{array}$ \\
\hline $\begin{array}{l}\text { 9. Ciudades } \\
\text { Educadoras }\end{array}$ & $\begin{array}{l}\text { En este momento se realiza una salida a la ciudad de Pontevedra, la primera de } \\
\text { las ciudades españolas acreditada como ciudad educadora, en este sentido se } \\
\text { realizan diferentes cuestiones a los responsables para poder identificar } \\
\text { fortalezas y debilidades de este modelo. Al tiempo se comparan con otros } \\
\text { modelos de urbe incluso de gran tamaño (Fernando y Morell, 1990) }\end{array}$ \\
\hline $\begin{array}{l}\text { 10. Reflexión personal: } \\
\text { Que fue para nosotras } \\
\text { el primer año de } \\
\text { Educación Social }\end{array}$ & $\begin{array}{l}\text { La última publicación tiene como objetivo un proceso de reflexión de su primer } \\
\text { año de Universidad (a nivel personal) y de los contenidos asimilados en la materia } \\
\text { (a nivel profesional). Para ello deben contrastar lo aprendido con su situación } \\
\text { previa al acceso formativo. }\end{array}$ \\
\hline
\end{tabular}

En los proyectos de aprendizaje-servicio, uno de los factores clave es conectar el servicio con los aprendizajes curriculares (Sotelino et al., 2019). En este sentido, en el marco de la materia de Pedagogía Social se han trabajado temáticas propias de la guía docente como: educación permanente, movimiento de las ciudades educadoras, administración local y educación social, animación sociocultural, o teorías y paradigmas de la pedagogía social. Pero, además, el alumnado tiene que entender esta dinámica en el marco de su titulación completa procurando una formación holística. De este modo, han podido plantear e implementar un proyecto educativo, diseñar recursos didácticos, indagar en la identidad profesional del Educador/a Social, investigar sobre gestión de la diversidad, gestión pedagógica de las TICs... Y como no, han optimizado aprendizajes para la vida y/o transversales como el trabajo en equipo, desarrollo de resiliencia, promoción de habilidades socio-relacionales e incluso gestión de recursos digitales. Es por ello, que el aprendizaje-servicio constituye una estrategia pedagógica idónea si pretendemos formar profesionales comprometidos.

El desarrollo e implementación de "Proaccionsocial" contó finalmente con la participación de nueve grupos de clase de la materia, con un total de 80 participantes de media. Cada uno de los grupos, de entre 7 y 9 miembros, escogía a una persona cada semana que estaba obligada a mandar la respuesta a los planteamientos de contenidos realizados y enviar las imágenes que sus compañeras le adjuntaban. De esta manera, absolutamente todo el alumnado se responsabilizó, al menos una vez, de participar en cada una de las actualizaciones semanales, siendo esta una de las premisas del trabajo cooperativo planteado.

Cabe señalar una cuestión que no es baladí, puesto que en este tipo de proyectos corremos el riego de que algún alumno/a no haga uso de redes sociales por motivos económicos, sociales o puramente circunstanciales. En este sentido cabe señalar que se ha facilitado el acceso de todo el alumnado a esta plataforma, aprovechando las instalaciones propias de la Universidad y, auspiciando entre compañeros/as las tareas colaborativas. De hecho, todos/as las/os participantes cuentan con un dispositivo móvil con el que realizar fotografía con calidad estándar y acceso a red de datos WIFI en el propio Campus, por lo que no se han detectado limitaciones en el proceso. De esta manera, teniendo en cuenta estos factores, se trató con equidad a cada una de las personas inmersas en la actividad, algo con lo que debemos ser sumamente cuidadosos (Colás et al., 2012). 
Una última fase, la cuarta, hace referencia a la evaluación del proyecto. Utilizamos una evaluación formativa y continúa haciendo entregas semanales en función de las temáticas. En cada uno de estos entregable debe figurar una imagen por alumno/a y dos textos descriptivos donde se trabaje el contenido concreto y una reflexión personal. Este registro se documenta en una lista de control propia y también en la plataforma virtual de la Universidad. De este modo, para acreditar que el trabajo estaba realizado y que cada apartado se correspondía con la propuesta tendría que figurar la correspondiente tarea semanal como entregada, y así posteriormente el profesor puede hacer un feedback que oriente el trabajo.

En cuanto a los indicadores de calidad empleados para la evaluación cabe señalar varias cuestiones. En primer lugar, aunque el número de likes puede estar condicionado por diversos factores ajenos al propio proceso (que se comparta en redes personales por los alumnos a los que se escogió la imagen; que se etiquete a diferentes organismos y den difusión sólo a esa publicación; que sea un tema muy específico y con alta sensibilidad entre el alumnado), es un indicativo cuantitativo interesante a la hora de recoger cuantas interacciones (a través de "like" o "historias"), ya que permite intuir el tipo de publicación que interesa más entre los seguidores/as al perfil. También, a la hora de valorar la calidad de las publicaciones, se debe justificar el hecho de que las imágenes y los textos fuesen de calidad en su formato, redacción y contenido, y para ello se procura la clara conexión curricular con la materia y la titulación en curso, que al fin y al cabo debe ser la motivación central de este proyecto.

Para facilitar el movimiento de fotografías y textos, y su difusión entre las compañeras/os del aula, se habilitó a través de la plataforma de Google Drive una carpeta compartida única con el número de cada uno de los grupos. De este modo, podemos rescatar cada una de las propuestas del alumnado, y tener como referencia el trabajo del grupo aula.

Finalmente, cabe destacar que el porcentaje otorgado a este proyecto de aprendizaje-servicio sobre la evaluación final de la materia, equivale al $20 \%$ de la nota final. Durante los cuatro años de la experiencia, este porcentaje no ha variado, y creemos que responde a la dedicación interactiva de la asignatura. Además, esta implicación resulta obligatoria para todo el alumnado, incidiendo en los beneficios académicos, personales y sociales que esta experiencia puede revertir en todos/as y cada uno de ellos/as.

\section{MÉTODO}

El proyecto "Proaccionsocial" nacía buscando la difusión y proyección del perfil profesional de los/as educadores/as sociales, junto con la sensibilización de en relación a ciertas temáticas de índole social. En este sentido, en la primera edición de esta experiencia (2017/2018), el perfil obtuvo la cifra de 600 seguidores, con un número mínimo de 100 interacciones en cada una de sus publicaciones. Estas consistían principalmente en likes, aunque cabe señalar que en ciertos temas se profundizó en el debate respecto a los contenidos con comentarios y aportaciones extra. En los años posteriores (curso 2018/2019, 2019/2020 y 2020/2021), se consolida la tendencia aumentando followers en cada edición, y manteniendo la asiduidad de publicación (Ver figura 1).

En este proyecto se han implicado una media de 80 alumnas/os por curso, sumando un total de 321 participantes (79 en el 2017/2018, 82 en el 2018/2019, 81 en el 2019/2020 y 79 en 
2020/2021, participando la totalidad del grupo de la materia de Pedagogía Social. Cabe señalar que al ser una materia obligatoria de primer curso, la matrícula es bastante estable en el tiempo y tan solo se ve afectada por algún abandono prematuro o bien segundas matriculaciones.

\section{Figura 1}

\section{Evolución de seguidores e impacto del proyecto}

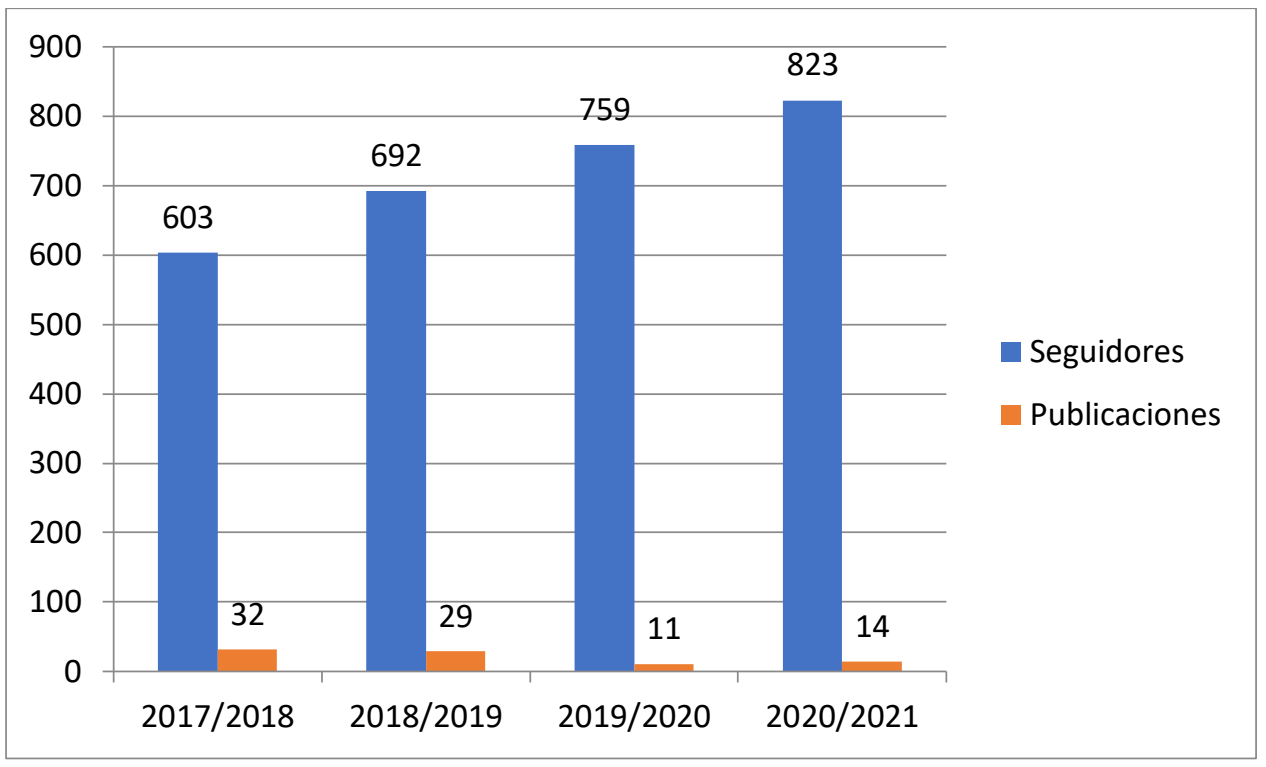

Para el análisis de este proyecto se ha utilizado una metodología mixta que ha combinado el análisis cualitativo realizado a partir de los informes de trabajo, las reflexiones grupales en las múltiples sesiones de seguimiento y un análisis de contenido de los comentarios vertidos en las publicaciones. Para ello, el profesorado de la materia ha usado diarios de campo donde reflejaba las anotaciones resultantes de la experiencia, y también se han analizado pormenorizadamente las opiniones y valoraciones personales de las memorias individuales entregadas. También contamos con un análisis descriptivo de algunos datos cuantitativos derivados del impacto de las publicaciones en la plataforma Instagram. En este segundo nivel se han tenido en cuenta indicadores como: número de seguidores, comentarios volcados, interacciones y visualizaciones de contenido.

Es importante destacar que el análisis se realiza de manera longitudinal a lo largo de las cuatro ediciones completadas del proyecto de aprendizaje-servicio. De este modo, podemos comparar la evolución realizada y hacer autocrítica sobre algunas cuestiones a optimizar. Por tanto, los resultados obtenidos responden al intervalo de cursos 2017/2018 a 2020/2021.

\section{RESULTADOS}

En primer lugar, cabe señalar que en cuanto a las intervenciones de aula, el hecho de que despertase interés el mundo tecnológico y virtual, ya era una oportunidad para aprovechar en el complejo ejercicio de transmitir conocimientos, que a diario era percibido como restricciones y materia obsoleta, y que debía formular un equilibrio entre el deseo de adquirir las competencias mínimas y transmitirlas públicamente, con las normas existentes tanto en el 
ámbito virtual, como en su ámbito personal y social. De este modo, se puede deducir que el mensaje a transmitir llegará mejor cuanto mayor sea la motivación del grupo y el interés suscitado a través de la fuente, partiendo del uso que hacen de su entorno virtual y las situaciones con las que se encuentran habitualmente nada tienen que ver con el aspecto formal educativo (López-Berlanga y Sánchez-Romero, 2019; Peña et al., 2018).

A partir de las opiniones vertidas por el alumnado en sus memorias individuales podemos extraer algunas cuestiones que influyen en el desarrollo e implementación, y que a su vez han de servir como acicate para la mejora de los procesos en este y otros proyectos de índole similar. En primer lugar, destacaban el escaso tiempo de mediación entre alumnado, tan sólo 90 minutos semanales de aula, limitaba en parte la relación y interacción con el docente, por lo que a veces, integrar de manera crítica los supuestos teóricos, pedagógicos, culturales y políticos era complejo pero necesario, ya que estaban incorporados en la base de los procesos de intervención socioeducativa, además de que son de debido cumplimiento en el desarrollo curricular de la materia. En este sentido, y como respuesta a esta demanda, en las cuatro ediciones se ha ido ponderando progresivamente el desarrollo teórico-práctico de manera equilibrada, y buscando también el fomento del autoaprendizaje, algo que se ha visto claramente necesario e inevitable en el curso 2020/2021 por las circunstancias anteriormente citadas. Por otro lado, citaban la dificultad existente para ofrecer un servicio de calidad desde las redes sociales, con el desconocimiento que tenían del mundo de la comunicación, dado que su perfil formativo es puramente pedagógico. En este sentido, el profesorado ha optado por potenciar el perfil didáctico de las publicaciones, reforzando este contenido transversal a las titulaciones de Educación.

Los aspectos anteriormente citados nos interesan mucho con el fin de situar al alumnado en el marco de un proyecto de aprendizaje-servicio, y no en otra dinámica pedagógica. Cabe señalar que las sesiones de reflexión grupal donde profesorado y alumnado poníamos sobre la mesa problemáticas, desafíos y oportunidades para la consecución de los objetivos de "Proacciónsocial", servían a su vez para resituar la conexión de la práctica con el curriculum de la materia de Pedagogía Social. Es por ello, que desde la coordinación del proyecto se instaba a recoger estas valoraciones y reflexiones en las memorias individuales que posteriormente serían entregadas y valoradas. También, se recogían anotaciones en un diario de campo, las cuales servirán para analizar el proceso seguido. En este sentido, es muy destacable el esfuerzo realizado por el alumnado en las memorias para la utilización de vocabulario profesional, identificación de ejemplos, relación de paradigmas con las prácticas reales..., algo que nos da idea de que el proceso de aprendizaje sobre el cual se basa el ApS asemeja resultar exitoso.

Por otro lado, la valoración por parte de reproducciones, de likes (figura 2) y de comentarios (figura 3), en un principio fomentó que la energía se destinase al impacto cuantitativo en redes, más que a cultivar las relaciones interpersonales en la corta distancia. La posible necesidad de llamar la atención con la propuesta didáctica no tenía en la Red su base, si no que casi se convirtió en una cuestión personal. Sentirse reconocidas pudo llevar a una dependencia y presión grande al comienzo de la experiencia, aunque a medida que avanzó el cuatrimestre, esta tensión desapareció, dando lugar a respuestas más centradas en explicar contenidos, que generar reacción entre la audiencia virtual. Esto explica el exponencial crecimiento de seguidores en la primera edición con su moderado aumento en los dos cursos posteriores, donde el docente ya calibró desde un inicio esta conducta (ver figura 1). El uso del móvil, 
aunque no está prohibido en todas las aulas, no se utilizaba en las mismas. Curiosamente, este periodo de clase, compartido por todas las jóvenes, alimentó la oportunidad para centrar su atención en reflexionar sobre su uso y el modo en que se utiliza. Con una generación que recibe tantos estímulos, es muy adecuado hablar de normas consensuadas y compartidas.

\section{Figura 2}

Interacciones en el proyecto "Proaccionsocial"

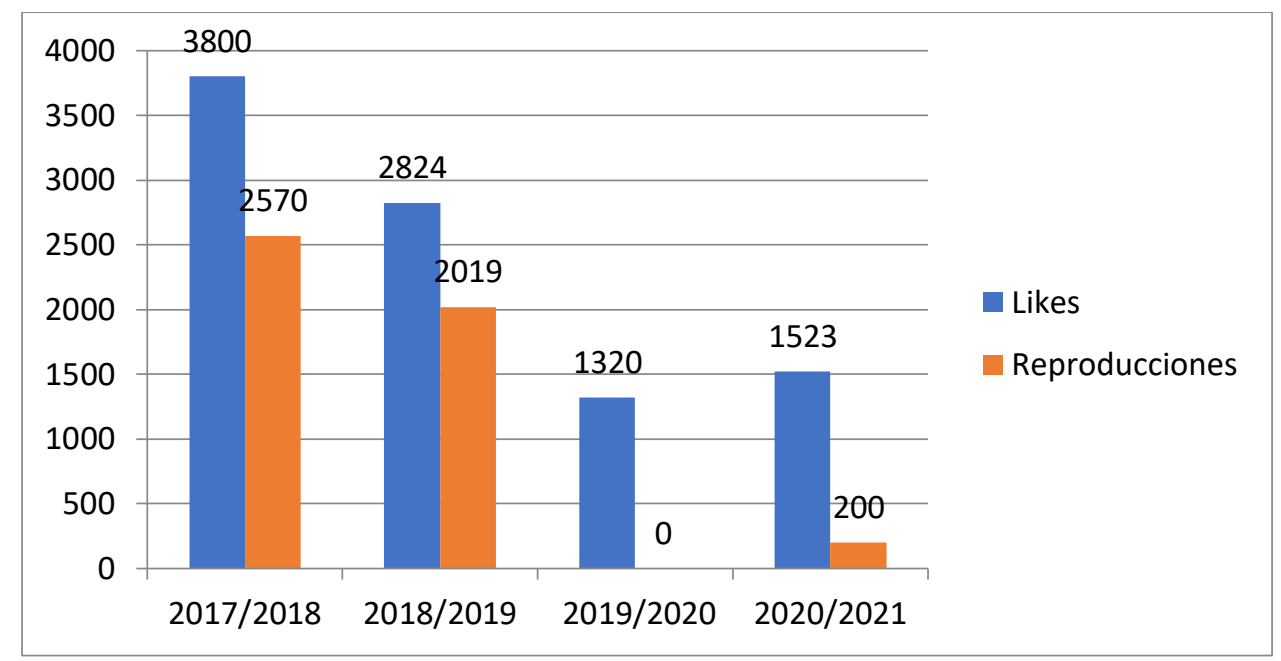

\section{Figura 3}

\section{Comentarios en el proyecto "Proaccionsocial"}

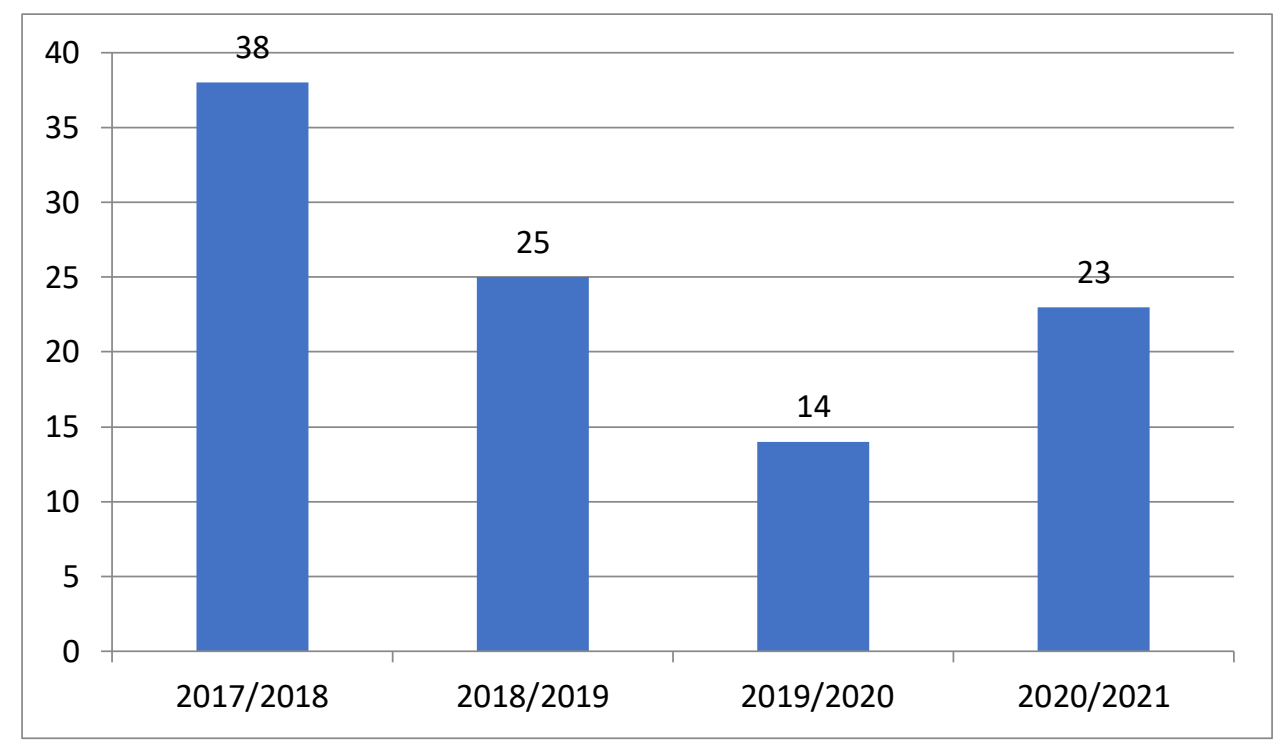

Tal y como podemos observar en las figuras anteriores, el decrecimiento intencionado de publicaciones para controlar el obsesivo aumento de followers, se ha notado en la cantidad de likes, comentarios y reproducciones obtenidas; pero si calculamos la proporción entre publicaciones y su impacto, podemos observar que mantiene constante (Tabla 4). Así la media general de estos tres cursos en relación a likes es de 111,22 con una DT=9,104 (118,75 en 2017/2018; 97,37 en 2018/2019; 120 en 2019/2020 y 108,78 en 2020/2021). Sucede 
igualmente con la proporción entre comentarios y publicaciones (Tabla 5) con una media de 1.257 comentarios por publicación, y DT= 0,265 (1,19 en 2017/2018; 0,9 en 2018/2019; 1,3 en $2019 / 2020$ y 1,64 en $2020 / 2021$ ).

\section{Tabla 2}

Proporción entre publicaciones e impacto

\begin{tabular}{lccc}
\hline Curso & $\begin{array}{l}\text { Proporción } \\
\text { publicaciones/likes }\end{array}$ & DT & Media \\
\hline $2017 / 2018$ & 118,75 & 9,104 & 111,22 \\
$2018 / 2019$ & 97,37 & & \\
$2019 / 2020$ & 120 & & \\
$2020 / 2021$ & 108,78 & \\
\hline
\end{tabular}

\section{Tabla 3}

Proporción entre publicaciones y comentarios

\begin{tabular}{lccc}
\hline Curso & $\begin{array}{l}\text { Proporción } \\
\text { publicaciones/comentarios }\end{array}$ & DT & Media \\
\hline $2017 / 2018$ & 1,19 & 0,265 & 1,257 \\
$2018 / 2019$ & 0,9 & & \\
$2019 / 2020$ & 1,3 & & \\
$2020 / 2021$ & 1,64 & & \\
\hline
\end{tabular}

Tampoco es baladí, el valor afectivo existente en los proyectos de aprendizaje-servicio (SantosRego et al., 2016), algo que no ha sido ajeno a Proacción Social, ya que la interacción también se producía desde sus cuentas personales, son espacios de expresión cultural y artística asequibles para cualquier persona que, por lo menos hace unos años, no tendría la posibilidad para poder manifestar todas aquellas inquietudes que demostraba (Calvo y San Fabián, 2018). Son sujetos activos y con necesidades de reconocimiento. De hecho, la posibilidad de cuantificar visitas o interacciones puede facilitar la valoración objetiva de diversas aportaciones culturales. Teniendo en cuenta que los entornos virtuales en ocasiones magnifican ciertas opiniones, que para nada son compartidas por la generalidad, pero que se pueden interpretar con vehemencia dependiendo del discurso o de la persona que lo esgrime.

Finalmente, a través de las intervenciones, observamos cierta diversidad en sus propuestas y motivos que cada persona tiene a la hora de escoger un tema. ¿Plantean una foto a Instagram 
con el mismo objetivo? ¿Utilizan la Red como trampolín de sus creaciones e imágenes? Lógicamente, no se puede aseverar una respuesta concreta. Las motivaciones son diversas y, aunque la plataforma escogida sea la misma y, la acción sea similar, las implicaciones son distintas. Pero los resultados obtenidos tanto cualitativa como cuantitativamente parecen indicar que resultados y objetivos se corresponden con la finalidad inicial del proyecto, puesto que se ha llegado a una población de iguales (jóvenes) que utilizan Instagram como vía de comunicación, pero lo más importante, como fuente de información.

\section{DISCUSIÓN Y CONCLUSIONES}

La creación de un perfil de Instagram, para trabajar contenidos explícitos dentro de la materia de Pedagogía Social, se antojaba por un lado novedosa, debido a la inexistente variedad de propuestas didácticas similares existentes en el Curso de 1으 de Educación Social y por otro compleja, entendiendo que el éxito o no de la actividad dependería en parte del grado de motivación del alumnado, que tiene como objetivo prioritario siempre, en una materia oficial, ser apta en cuanto a la calificación final. El hecho de que las estudiantes pudieran explicar sus conocimientos, su futuro trabajo o vocación de una forma distinta, facilitó también la adquisición de competencias a través de la defensa de argumentos y la resolución de problemas dentro de su área de estudio. Asimismo, demostraron poseer y comprender conocimientos en un área de estudio totalmente nueva para la mayoría, que, aunque partiendo de la base de la educación secundaria general y, en algún caso de ciclos superiores de ramas afines, incluía algunos aspectos que implicaban conocimientos procedentes de su historia vital y el uso diario de redes sociales como método de socialización. Es por ello, que la metodología aprendizaje-servicio, con su vertiente más virtual, se mostraba como la mejor opción de desarrollar esta acción por conectar práctica profesional (identificación de ámbitos de intervención socioeducativa) con el curriculum de la citada materia, por medio de una reflexión guiada en las sesiones de aula.

La intervención expuesta, no se centró en aspectos legales o prohibitivos, si no que, asumiendo ese uso que puede existir y que se iba a impulsar, fuesen capaces de trabajar aspectos relacionados con su profesión y la resolución de conflictos. Una oportunidad única, ya que esta intervención aceptaba la diversidad, y profundizaba en los motivos por el cual la formación reglada no atendía a las necesidades educativas de la juventud. $Y$, al mismo tiempo, reconciliamos al alumnado de primer curso de esta titulación con su vocación, ya que muchas veces sus expectativas formativas no se responden a su ingreso en la Academia, por lo que así reivindican su posición formativa y profesional (Bonetti, 2020; González-Alemán, 2008).

Se puede confirmar a través de esta propuesta que las tecnologías eran y son un sistema de relación y comunicación totalmente asentado. Aunque no existiese una o varias entidades asociadas al proyecto, algo que se suele dar en las iniciativas de ApS, el servicio realizado pasaba por evidenciar problemáticas sociales generando debate en redes, pero mediadas por educadores/as sociales en formación. Así, se daría cumpliento a los objetivos inicialmente propuestos de poner en valor la profesión de Educación Social al tiempo que informar, difundir y contrastar información sobre colectivos sociales a partir del conocimiento científico-técnico. Por lo que el colectivo de los/as destinatarios/as potenciales era muy abierto, y se ha visto concretado en cientos de jóvenes followers que seguían los perfiles habilitados. 
Además, cabe resaltar que alumnas y alumnos conocen y están al día de aquellas aplicaciones que pueden resolver cualquier problema relacionado con su edad e incluso con sus estudios: búsqueda de información para clase, métodos de comunicación inmediatos, relaciones con personas que no son de su entorno más cercano (Peña et al., 2018). Sabíamos y aceptábamos que las redes sociales son espacios de relación interpersonal, y que detrás de su uso, aparecían comportamientos relacionados con la autoestima, con los gustos personales, o incluso, con la necesidad de llamar la atención. La inmediatez de esos mensajes, la posibilidad de contactar en cualquier momento, de compartir archivos o fotos, crea un microsistema de relaciones particular con el que se generan códigos comunicativos (Bonetti, 2020). Por ello, la intervención social en estos entornos tiene su sentido y también se ha puesto de manifiesto a lo largo del proyecto identificando perfiles que generaban odio o promovían fake news.

En contraste también con los mensajes que hablan en la juventud de un uso excesivo se valoró como elementos de los que pueden prescindir en sus momentos de ocio, ya no tanto si necesitan una información muy concreta. Por tanto, el tiempo de aulas y de estancia en el Campus podía ser suficiente para realizar su cometido satisfactoriamente. Además, en las instalaciones universitarias cuentan con acceso a internet que en muchos hogares carecen.

Trabajamos, y es un aspecto clave en la formación de futuras/os educadoras/es sociales, la necesidad de entender que somos personas diversas, que cada una de ellas tiene una vida no virtual, y que los mensajes o imágenes enviadas, no iban a ser entendidas o asimiladas como nosotros queríamos. De hecho, recalcamos que, en una comunicación verbal puede suceder que no consigamos explicarnos o bien, la persona receptora del mensaje entiende de manera distinta lo que tratamos de exponerle. ¿Tenemos las herramientas para conseguir expresarnos y resolver conflictos que surgen a diario? Está claro que no.

Por todo ello, las posibilidades universales que ofrece el aprendizaje-servicio virtual, en este caso mediante la simple creación de un perfil de Instagram, son mucho más grandes que las limitaciones o peligros que podemos conocer. En líneas generales, su día a día no se centra únicamente en participar en el espacio virtual, si no que es la comunicación existente a día de hoy en toda la sociedad y prácticamente en todas sus franjas de edad. Es necesario asumir desde la Universidad que los entornos virtuales son espacios asentados, dependerá del uso que les demos y, que pueden ser un compañero de viaje muy atrayente si lo utilizamos para trabajar contenidos académicos y si sorprendemos al alumnado con nuestros conocimientos actualizados. Centrar el discurso en su autonomía y en sus capacidades es fundamental, al tiempo que podemos utilizarlos para cubrir necesidades sociales de reciente creación (Sotelino et al., 2020). De esta manera, se puede facilitar procesos positivos respecto a la adquisición de competencias online $y$, generar una convivencia virtual mucho más activa, implicada y socialmente responsable. Desde luego el reto es enorme y el momento ha llegado.

\section{REFERENCIAS}

Barba, C. y Capella, S. (Coords.) (2010). Ordenadores en las aulas: la clave es la metodología. Graó.

Blaszczynsky, A. (2006). Internet use: In search of an addiction. International Journal of Mental Health and Addiction, 4, 7-9. 
Bonetti, O. (2020). Algunos retos a la educación superior universitaria enseñar a nuevas generaciones ¿'millennials' y 'centennials'?. Revista Methodo: Investigación Aplicada a las Ciencias Biológicas, 5(1), 2-3. https://doi.org/10.22529/me.2020.5(1)02

Bonilla, R., Perea, E., y Del Olmo, J.L. (2019). Instagram as a communication tool in higher education: A case study. En M. P. Bermúdez (comp.), Evaluación de la calidad de la investigación y de la educación superior: XVI FECIES. Libro de actas (pp. 550-551). Granada: Asociación Española de Psicología Conductual (AEPC).

Calvo, S. y San Fabián, J.L. (2018). Selfies, jóvenes y sexualidad en Instagram. Representaciones del yo en formato imagen. Pixel-Bit: Revista de medios y educación, 52, 167-181. https://doi.org/10.12795/pixelbit.2018.i52.12

Caride, J.A. (2005). Las fronteras de la pedagogía social, perspectivas científica e histórica. Gerisa

Castellana, M., Sánchez-Carbonell, X, Beranuy, M., y Graner, C. (2006). La relació de I'adolescent amb les TIC: Un tema de rellevància social. Full informatiu del Col-legi oficial de Psicòlegs de Catalunya, 192, 22-23.

Castillejos, B. (2019). El autoconcepto de los millennial's como aprendices y la autorregulación y motivación por el aprendizaje permanente. Revista Iberoamericana de Educación, 79(2), 81-98. https://doi.org/10.35362/rie7923238

Cervera, L. (2009). Lo que hacen tus hijos en Internet. Integral.

Christahkis, N.A. y Fowler, J. H. (2010). Conectados. El sorprendente poder de las redes sociales y cómo nos afectan. Taurus.

Colás, P., González, T., y de Pablos, J. (2013). Juventud y redes sociales. Motivaciones y usos preferentes. Comunicar: Revista científica iberoamericana de comunicación y educación, 40, 15-23. http://dx.doi.org/10.3916/c40-2013-02-01

Cotino, L. (ed.) (2010). Libertades de expresión e información en Internet y las redes sociales: ejercicio, amenazas y garantías. Programación y contenidos de la televisión e Internet: la opinión de los menores sobre la protección de sus derechos. Universidad de Valencia. Defensor del Pueblo.

Echeburúa, E. (2010). Adicción a las nuevas tecnologías y a las redes sociales en jóvenes: un nuevo reto. Adicciones, 22(2), 91-96.

Escandell, D. (2020). Lecturas juveniles mediadas por las TIC pantallas, mundo digital y transmedialidad. Presencias y percepciones entre estudiantes. Contextos educativos: Revista de educación, 25, 91-103.

Fernández-Rodríguez, J.J. (2004). Secreto e intervención de comunicaciones en Internet. II Estudio sobre los hábitos de uso en Internet entre jóvenes de 12 a 17 años. Civitas Fundació Catalana per a la Recerca.

Fernando, J. y Morell, S. (Coords.) (1990). La ciudad educadora. I Congres Internacional de Ciutats educadores. Ajuntament de Barcelona. 
García-Gutiérrez, J., Ruiz-Corbella, M., y Del Pozo, A. (2017). Developing civic engagement in distance education: A case study of virtual service-learning (VSL) programme in Spain. Open Praxis, 9(2), 235-244. http://dx.doi.org/10.5944/openpraxis.9.2.578

García-Gutiérrez, J., Ruíz-Corbella, M., y Manjarrés-Riesco, A. (2021). Virtual Service-Learning in Higher Education. A Theoretical Framework for Enhancing its Development. Frontiers in Education, 5(630804), 1-10. https://doi.org/10.3389/feduc.2020.630804

García-Ruíz, R., Tirado, R., y Hernando, A. (2018). Redes sociales y estudiantes: motivos de uso Y gratificaciones. Evidencias para el aprendizaje. Aula abierta, 47(3), 291-298. https://doi.org/10.17811/rifie.47.3.2018.291-298

Gómez-Arruzazabala, G. (2019). Instagram para el fomento de la Educación Física. Lecturas: Educación física y deportes, 24 (254), 89-100.

González-Alemán, J.L. (2008). El estudio del abandono universitario. Anaga.

González-Hernando, C., Valdivieso-León, L., y Velasco, V. (2020). Estudiantes universitarios descubren redes sociales y edublog como medio de aprendizaje. RIED: revista iberoamericana de educación a distancia, 23(1), 223-239. https://doi.org/10.5944/ried.23.1.24213

Gracia, M., Vigo, M., Fernández, Mạ J., y Marcó, M. (2002). Problemas conductuales relacionados con el uso de Internet: un estudio exploratorio. Anales de Psicología. 18(2), 273-292.

INJUVE (2009). Adolescentes y jóvenes en la Red: factores de oportunidad. Instituto Nacional de Estadística.

INTECO- Instituto Nacional de Tecnologías de la Comunicación (2009). Estudios sobre la privacidad de los datos personales y la seguridad de la información en las redes sociales online. Agencia Española de Protección de Datos.

López-Berlanga, M.C. y Sánchez-Romero, C. (2019). La interacción y convivencia digital de los estudiantes en las redes sociales. Revista de Educación Inclusiva, 12(2), 114-130.

Martínez-Salanova, E. (2002). Aprender con el cine, aprender de película. Una visión didáctica para aprender e investigar con el cine. Grupo Comunicar

Peña, M.A., Rueda, E, y Pegelar, M.C. (2018). Posibilidades didácticas de las redes sociales en el desarrollo de competencias de educación superior: Percepciones del alumnado. PixelBit: Revista de medios y educación, 53, 239-252. https://doi.org/10.12795/pixelbit.2018.i53.16

Pérez-Escoda, A. (2018). Uso de smartphones y redes sociales en alumnos/as de Educación Primaria. Prisma Social: revista de investigación social, 20, 76-91.

Petrus, A. (1997). Pedagogía Social. Barcelona: Ariel.

Roig, A. (2010). Derechos fundamentales y tecnologías de la información y de las comunicaciones (TICS). JB Bosch. 
Romero, J.M., Campos, N. y Gómez, G. (2019). Follow me y dame like Hábitos de uso de Instagram de los futuros maestros. Revista interuniversitaria de formación del profesorado, 94, 83-96. https://doi.org/10.47553/rifop.v33i1.72046

Ruiz-Olivares, R., Lucena, V., Pino, Mạ. J., y Herruzo, J. (2010). Análisis de comportamientos relacionados con el uso/abuso de Internet, teléfono móvil, compras y juego en estudiantes universitarios. Adicciones, 22(4), 301-310.

Santos-Rego, M.A., Lorenzo, M., y Priegue, D. (2009). Aprendizaje cooperativo práctica pedagógica para el desarrollo escolar y cultural. Magis: Revista Internacional de Investigación en Educación, 1(2), 2009, 289-303.

Santos-Rego, M.A., Sotelino, A., y Lorenzo, M. (2016). El aprendizaje-servicio en la educación superior una vía de innovación y de compromiso social. Educación y diversidad: Revista inter-universitaria de investigación sobre discapacidad e interculturalidad, 10(2), 17-24

Santos-Rego, M.A., Mella, I., y Sotelino, A. (2020). Movilidad y TIC en aprendizaje-servicio: perspectivas para una sociedad global y tecnológica. RIED: revista iberoamericana de educación a distancia, 23(1), 67-84. https://doi.org/10.5944/ried.23.1.24180

Sotelino, A. (2019). Educar para la responsabilidad. Una Universidad en diálogo con la comunidad. En V. Arufe (ed.), 50 historias de éxito docente (pp. 39-48). Educa.

Sotelino, A., Santos-Rego, M.A., y Lorenzo, M. (2016). Aprender y servir en la universidad: una vía cívica al desarrollo educativo. Teoría de la educación, 28 (2), 225-248. https://doi.org/10.14201/teoredu282225248

Sotelino, A., Mella, I, y Rodriguez-Fernández, M.A. (2019). El papel de las entidades cívicosociales en el aprendizaje-servicio: sistematizando la participación del alumnado en el tercer sector. Teoría de la educación, 31 (2), 197-219. https://doi.org/10.14201/teri.20156

Sotelino, A., Mella, I., y Varela, C. (2020). Aprendizaje-servicio, TIC y conocimiento compartido para promover la reflexión en red. Cuaderno de Pedagogía Universitaria, 17(34), 19-30. https://doi.org/10.29197/cpu.v17i34.393

Waldner, L. S., McGorry, S. Y., y Widener, M. C. (2012). E-service-learning: The evolution of service-learning to engage a growing online student population. Journal of Higher Education Outreach and Engagement, 16(2), 123-150.

\section{Para citar este artículo:}

Sotelino-Losada, A., y Brea Castro, M. (2021). Aprendizaje-Servicio Virtual y Pedagogía Social. El proyecto ProAcción Social. Edutec. Revista Electrónica De Tecnología Educativa, (78), 38-53. https://doi.org/10.21556/edutec.2021.78.2251 